\title{
Saúde mental nos municípios do Alto Uruguai, RS, Brasil: um diagnóstico da reforma psiquiátrica
}

\author{
Mental health in the cities in Alto Uruguai, RS, Brazil: \\ a diagnosis of the psychiatric reform
}

Gelson Luiz Consoli ${ }^{1}$

AliceHirdes ${ }^{2}$

Juvenal Soares Dias da Costa ${ }^{3}$

${ }^{1}$ Curso dePós-Graduação em SaúdePública,

Departamento deCiências daSaúde, Universidade

Regional Integrada do Alto Uruguai e da M issões.

Av. 7 deSetembro 1621, 99700-000 Erechim RS. gelson_consoli@yahoo.com ${ }^{2}$ Departamento deSaúde, Universidade Luterana do Brasil.

${ }^{3}$ Programa de Pós-

Graduação em Saúde Coletiva, Universidade do Vale do Rio dos Sinos.
Abstract This study investigated the characteristics of mental healthcarein the cities situated at the Alto U ruguai from the perspective of the guidelines of the Brazilian Health System (SUS), and of the Psychiatric Reform. Based on a structured tool, we interviewed 31 subjects working in the public care network. The results point to centralized actions and "medicalization" of symptoms in the clinical care model although all cities count on Family $\mathrm{H}$ ealth Programs; lack of integrated care in mental health; inexistence of a mental health service network in the cities except in the main city; transfer to psychiatric hospitals to solve acute and chronic cases; lack of follow-up after the patient is released from the psychiatric hospital characterizing the phenome non of the revolving door; the inexistence of mental health programs in the Health Policies of the city; and the weak representation of these professionals in the $\mathrm{H}$ ealth Councils. We conclude that the transfer of the responsibility for mental healthcare to the local authorities in the northern region of Rio Grande do Sul is still incipient and that hospitalization in psychiatric hospitals continues the main intervention in the field of mental health. Key words M ental health, $\mathrm{H}$ ealth services, $\mathrm{H}$ ealth policy
Resumo 0 presenteestudo investigou as características dos cuidados em saúde mental nos municípios do Alto U ruguai, levando em conta as diretrizes do Sistema Ú nico deSaúde (SUS) eda Reforma Psiquiátrica. Através de um instrumento estruturado, foram entrevistados 31 profissionais queatuam na rede de saúde pública. Os resultados apontam a centralização das ações no modelo de atendimento clínico, na medicalização dos sintomas, embora a totalidade dos municípios disponha de Programas de Saúde da Família; a não utilização de conceitos de clínica ampliada na saúde mental; a inexistência de uma rede de serviços de Saúde M ental nos municípios, excetuando a cidade pólo; a utilização da transferência para hospitais psiquiátricos como solução para os casos agudos e crônicos; a ausência de acompanhamento posterior das equipes à internação em hospitais psiquiátricos, caracterizando a porta giratória; a inexistência de programas de saúde mental inseridos nos Planos M unicipais de Saúde; assim como a inexpressiva representatividade de profissionais nos Conselhos de Saúde. Conclui-se quea questão da municipalização da Saúde M ental na região norte do Rio Grande do Sul éincipiente, prevalecendo ainda as internações em hospitais psiquiátricos como principal intervenção em Saúde M ental.

Palavras-chave Saúde mental, Serviços de saúde, Política de saúde 
Introdução

A assistência em saúdemental, historicamente centrada no modelo hospitalocêntrico, desde os anos 1980 , tem passado por significativas mudanças no contexto da sociedade em que se vive. Esse processo, conhecido como desinstitucionalização em Saúde M ental ou Reforma Psiquiátrica, tem recebido a atenção de governantes e profissionais da área, respaldados nas Conferências de Saúde M ental, na legislação e nas portarias ministeriais. Um marco teórico importante na área da Saúde M ental para a América Latina é a Declaração de Caracas - que condena a exclusividadedada, até então, aos hospitais psiquiátricos como única forma de assistência às pessoas portadoras de um transtorno mental ${ }^{1}$.

No Brasil, a Reforma Psiquiátrica organiza-se com base nos pressupostos da Reforma Sanitária e da Psiquiatria Democrática Italiana, que prevêa de sinstitucionalização como desconstrução do modeIo manicomial, modificando o status quo por meio de novas estratégias que oferecem novas soluções 2 .

$\mathrm{Na}$ proposta atual da Reforma Psiquiátrica no Brasil, tem-se como objetivo a desinstitucionalização einclusão, integrando os sujeitos nos diferentes espaços da sociedade. A desinstitucionalização não deve ser praticada apenas no interior do hospital psiquiátrico, mas pressupõe a necessidade de de sinstitucionalizar o contexto, isto é, não basta ape nas modificar o espaço onde o tratamento se dá, faz-se necessário modificar a lógica institucionalizante e segregadora a fim de que os novos serviços não reproduzam o saber manicomial. No entanto, para que isto de fato aconteça, é preciso desinstitucionalizar os serviços, os profissionais e a sociedade para que estes possam estar abertos à construção de um novo saber/fazer em Saúde M ental ${ }^{3}$.

Para Amarante ${ }^{3-5}$, como desdobramentos da Reforma Psiquiátrica, tem-seo surgimento do conceito de Saúde M ental como um novo objeto, superando a idéia de prevenção das desordens mentais, para alcançar o projeto de promoção da Saúde $M$ ental, enquanto na concepção de Saracen $0^{6}, 0$ conceito de saúde mental congrega as noções da condição desejada de bem-estar dos indivíduos e das ações necessárias que possam determinar essa condição. Assim, saúde mental éum conceito amplo na medida em que considera as dimensões psicológicas e sociais da saúde e os fatores psicossociais que determinam o processo saúde-doença.

A partir dos marcos teóricos, dentre eles, a Declaração de Caracas, as Conferências Nacionais de Saúde M ental, assim como os marcos práticos - a interven ção na Casa de Saúde Anchieta, em Santos, a criação do Centro deAtenção Psicossocial (CAPS)
Luis Cerqueira, em São Paulo e do Centro Comunitário de Saúde M ental de São Lourenço do Sul, no Rio Grande do Sul, leis e portarias ${ }^{7-10}$ passaram a dar 0 embasamento legal para o desencadeamento da Reforma Psiquiátrica. Além disso, começou a delinear-se um novo modelo assistencial de Saúde Mental, substituindo o modelo manicomial por uma rede de serviços territoriais, de base comunitária, no qual os usuários têm à sua disposição equipes interdisciplinares para 0 acompanhamento terapêutico e transformam-se em agentes e sujeitos do próprio tratamento, ostentando uma condição de dignidade na busca de sua inserção social.

A Constituição Federal de 1988, no artigo 196, ao estabelecer que a saúde é um direito de todos e dever do Estado, garantido mediante políticas sociais e econômicas que visam à redução do risco de doença e de outros agravos e ao acesso universal e igualitário às ações e serviços para sua promoção, proteção e recuperação ${ }^{8}$ ensejou, como decorrência, uma ampla legislação complementar, como a Lei $n^{\circ} 8.069 / 90$, a Lei ${ }^{\circ} 8.080 / 90$, a Lei $n^{\circ} 8.142 / 92$, as Portarias do M inistério da Saúde n ${ }^{\circ}$ 189/91 e n 224/92, a Norma Operacional Básica/96, a Lei $n^{\circ}$ 10.216/01, além deleis enormas estaduais que dão sustentação aos entes federados para atender a saúde, e, em particular, a Saúde M ental7,9,11.

A 8a Conferência Nacional de Saúde coloca como responsabilidade da unidade básica 0 atendimento em $80 \%$ das necessidades da população, incluindo a Saúde M ental. Desta forma, torna-se necessário incluir a atenção aos portadores de sofrimento psíquico dentro da rede pública, mediante a oferta de ações locais, a potencialização de recursos comunitários, através da articulação das ações de assistência, promoção, prevenção e reabilitação psicossocial, implementando uma rede de serviços territoriais deSaúde M ental, substitutivos ao aparato manicomial.

A 3a Conferência Nacional de Saúde M ental reafirma a saúde como direito do cidadão e dever do Estado, afirmando a responsabilidade das três esferas de governo no que diz respeito às políticas de Saúde M ental seguirem a mesma direção dos princípios do SUS de ação integral, acesso universal e gratuito, eqüidade, participação e controle social, priorizando a construção da rede de atenção integral em SaúdeM ental. As políticas deSaúdeM ental devem estar embasadas nos seguintes pressupostos: inclusão social, desmistificação em relação à comunidade para que esta aprenda a conviver com a diferença. É imprescindível a intersetorialidade, isto é, a união das diferentes políticas sociais como educação, trabalho lazer, cultura, visando à real construção de dignidade e cidadania ${ }^{12}$. 
0 combate aos estigmas é a principal medida para garantir o sucesso da lei de Reforma Psiquiátrica. Esta lei seguea diretriz da OM S: garantir tratamento aos pacientes sem necessidade deinternação. Em dezembro de 2001 realizou-se a 3a Conferência de Saúde M ental, em Brasília, tendo como título, proposto pela Organização M undial deSaúde, "Cuidar sim, excluir não". Baseada na lei aprovada, procurou direcionar suas discussões, nos eixos temáticos: reorientação do modelo assistencial; recursos humanos e financiamento; controle social; acessibilidade, direitos e cidadania ${ }^{12}$.

O Rio Grande do Sul aprovou em 1992 a Lei Estadual no 9.716, que trata da reforma psiquiátrica em âmbito do estado 7 . Entretanto, o Rio Grande do Sul, um Estado pioneiro na aprovação de uma legislação específica na área, e detentor do maior número de Centros de Atenção Psicossocial (CAPS) por estado, apresenta diferenças regionais importantes na estruturação de serviços ${ }^{13},{ }^{14}$. Enquanto a metade sul protagonizou experiências inéditas de desinstitucionalização, o norteapresenta carência na estruturação de serviços e na inserção das ações de Saúde M ental nos serviços gerais de saúde. Entende-se queesta realidade descortina-se em outros estados e regiões, onde não há serviços de Saúde M ental estruturados e os equipamentos de saúde na atenção básica operam eminentemente no paradigma clínico (problema-solução).

A ênfase das ações de Saúde M ental no território constitui-se na própria essência da desinstitucionalização em psiquiatria, partindo do pressuposto de que a legislação delegou aos municípios a responsabilidade de gerir a saúde pública em sua área deabrangência administrativa, contando, para tanto, com a assistência técnica e financeira dos estados e da União.

Quanto mais o PSF estabelecer-se e capilarizar-se no município, mais deve integrar-se à rede de relações que vai sendo construída em torno da atenção à Saúde M ental. A construção que acontece é a de uma rede de relações sociais em busca de uma nova atitude diante dos problemas referentes ao processo saúde mental /sofrimento psíquico/ doença mental. Não apenas ligado ao modelo biomédico, que visa a prevenir agravos individuais, concebidos como naturais e produtos de uma história natural, mas articulada à cidade e ao cidadão, centro ativo de políticas e percepções críticas sobre a cultura ${ }^{15}$.

A efetivação da Reforma Psiquiátrica requer agilidade no processo de superação dos hospitais psiquiátricos juntamente com a criação dos serviços substitutivos, que garanta, além da inclusão social, a devolução de identidade e cidadania aos portadores de sofrimento psíquico. Assim, faz-se necessário que os municípios integrem uma rede de saúde que possibilite a realização de ações de proteção, promoção, prevenção, assistência e recuperação em saúde mental ${ }^{10}$. Desta forma, esta pesquisa poderá fornecer subsídios para o desenvolvimento de políticas públicas de Saúde M ental no contexto da atenção básica, especificamente, no Programa de Saúde da Família (PSF).

0 estudo teve como objetivo geral investigar as características dos cuidados em Saúde M ental nos municípios do Alto Uruguai, levando em conta as diretrizes do SUS e da Reforma Psiquiátrica. Os objetivos específicos foram: conhecer a inserção da assistência em Saúde M ental nos planos municipais desaúde; identificar o tipo deassistência prestada nos diferentes níveis de atenção; investigar a existência de programas municipais de atenção à Saúde M ental; levantar quantos e quais são os profissionais envolvidos na assistência em SaúdeM ental em cada município; investigar os padrões de referência e contra-referência intra e intermunicípios; identificar a representação da Saúde M ental na composição do Conselho Municipal de Saúde; conhecer a alocação de recursos financeiros para a área da saúde e da Saúde M ental e identificar se a internação psiquiátrica em hospital psiquiátrico é vista como primeira ou última alternativa.

\section{Métodos}

A região do Alto Uruguai, situada no estado do Rio Grande do Sul, está compreendida por 31 municípios, que integram a 11a Coordenadoria Regional de Saúde. Os municípios pesquisados, com exceção de dois, possuem características demográficas bastante semelhantes, segundo dados estatísticos fornecidos pelo Instituto Brasileiro de Geografia eEstatística (IBGE) ${ }^{16}$, ano base 2000 , que aponta um (1) com população acima de 90.000 habitantes; um (1) na faixa de 10.001 a 20.000 habitantes; nove (9) com população entre 5.001 e 10.000 habitantes evinte (20) com população inferior a 5.000 habitantes. Quanto às condições socioeconômicas e culturais, também há muita semeIhança, assentando-se na agricultura o sustentáculo econômico; a população, etnicamente, écomposta de descendentes de italianos, alemães, poloneses e afro-brasileiros. Houve concordância entreas informações fornecidas pelos municípios em relação aos cuidados em Saúde M ental, caracterizando uma situação dehomogeneidade, incluindo o município pólo, quediferesomente pela existência de um CAPS. 
Durante os meses de junho ejulho de 2003, foram aplicados questionários padronizados contendo questões sobre a rede deSaúde M ental existente no município, tipos de atividades desenvolvidas pelos serviços, recursos humanos disponíveis para as atividades de Saúde M ental, fluxos de referência econtra-referência utilizados pelos municípios, representação da Saúde M ental na composição do Conselho Municipal de Saúde; alocação de recursos financeiros para a área da saúde e da Saúde M ental e a caracterização das transferências para hospitais psiquiátricos.

Os respondentes foram profissionais de nível superior dos 31 municípios pertencentes da região, médicos, enfermeiros e psicólogos, designados pelos secretários municipais de saúde correspondentes. Os dados foram analisados e apresentados de acordo com as distribuições das categorias.

Foram respeitados os aspectos éticos referentes à pesquisa com seres humanos, conforme determina a Resolução nº 196/96 ${ }^{17}$ e a Declaração de $\mathrm{H}$ elsinque ${ }^{18}$. Os entrevistados assinaram um termo deconsentimento livree esclarecido, no qual se explicitou o objetivo principal da pesquisa. Através de ofício, registrou-se um comprometimento explícito de que as informações não seriam reveladas de forma particularizada, garantindo, desta forma, o sigilo e anonimato dos entrevistados. A pesquisa foi submetida e aprovada pelo Comitê de Ética Institucional da Universidade, sob o protocolo no 020 - 1/THC/03.

\section{Resultados}

\section{Plano de Saúde M ental}

0 estudo questionou os municípios a respeito da existência ou não de um planejamento escrito para a área da Saúde M ental, ea resposta de 25,80\% deles foi de que o Plano de Saúde Pública contempla também a Saúde M ental, enquanto $74,20 \%$ informaram não possuir plano específico e que o assunto também não está contemplado no planejamento global da Secretaria Municipal da Saúde, não existindo, portanto, plano escrito para a Saúde M ental.

Rede municipal de serviços

na área da saúde mental

Quanto à existência de uma possível rede de serviços que contemplea área da Saúde M ental, os municípios apresentaram respostas que formam a seguinte realidade (Figura 1): 70,90\% prestam os serviços através das Unidades Básicas de Saúde (UBS); $54,80 \%$ os disponibilizam nosPSF e $35,40 \%$ através do Programa de Agentes Comunitários de Saúde (PACS). Destes, um percentual de 58,06\% 0 faz com a ajuda de um profissional de referência, comumente o psicólogo. Na mesma questão, $19,35 \%$ disseram possuir oficinas terapêuticas e 9,67\% disponibilizam leitos hospitalares em hospitais gerais. Q uanto à existência de ambulatório com equipe especializada de Saúde M ental, unidades psiquiátricas em hospitais gerais e CAPS, apenas 3,23\% responderam afirmativamente. Especificamente em relação ao ambulatório, este encontra-se na cidade pólo-regional, Erechim. Esta realidadevem ao encontro da assertiva quanto à questão de os municípios urbanos deterem o maior número de profissionais e serviços.

\section{Cuidados/atividades \\ desenvolvidos pelos municípios}

A Figura 2 traz a realidade relacionada com os cuidados/atividades desenvolvidos pelos municípios na área da Saúde M ental. Os números apontam que $100 \%$ dos municípios oferecem consultas com médico generalista aos portadores de transtornos mentais; $87,10 \%$ disponibilizam atendimento individual com psicólogo, através de profissionais do próprio quadro ou através de serviços adquiridos na região; $83,87 \%$ procedem a cadastramento das pessoas com patologias mentais, para fins de fornecimento de medicamentos, conforme normas do Ministério da Saúde. Atendimentos com médico psiquiatra acontecem em $19,35 \%$ dos municípios, sendo que, na maioria dos casos, os serviços são adquiridos de profissionais sediados na cidade-pólo regional, em razão da existência de médico psiquiatra somente em dois municípios.

A Figura 3 demonstra que prevalece a centralização na questão das consultas médicas com clínico geral e do cadastramento dos pacientes, objetivando o fornecimento de receitas. Entretanto, ao cruzar estas variáveis com as informações contidas na Figura 2, observa-se que não é a totalidade das Unidades de Saúde que desenvolvem atendimento em Saúde M ental, mas somente 22 municípios, o que representa um percentual de $70,90 \%$.

\section{Profissionais a serviço da Saúde Mental}

0 instrumento de pesquisa questionou sobrerecursos humanos disponíveis na região a serviço da Saúde M ental; os dados apontam que $100 \%$ dos municípios têm médico clínico geral e enfermeira, em função de a totalidade ter implantado o PSF. Em 
$74,20 \%$ dos municípios, constata-se a existência de auxiliar de enfermagem; em 70,90\%, de psicólogo; em $64,52 \%$, de assistente social; em 9,67\%, denutricionista; em 6,45\%, psiquiatra, técnico em enfermagem, fisioterapeuta e monitor, e em $3,23 \%$ dos municípios, existe terapeuta ocupacional e pedagogo.

Importante se faz destacar que, apesar do número de profissionais encontrar-se dentro do preconizado em termos quantitativos, em se tratando de equipes do Programa de Saúde da Família (PSF), na prática estes profissionais atendem a todos os tipos de demandas do município, dentre estes, escolas, asilos, creches. Assim, a atenção à Saúde $M$ ental perpassa fundamental menteo atendimento em situações agudas, o encaminhamento para outros serviços, comumente fora da região, sem um acompanhamento posterior. Via de regra, 0 agentecomunitário de saúde, empiricamente, intervém precocemente é e forçado a tomar decisões, que envolvem a solicitação de ajuda aos profissionais da equipe, acompanhamento à internação eo contato com os familiares.

\footnotetext{
Urgência/Emerg. em Saúde Mental no P.S. | 0,00\% Ambulatório c/ equipe de S. M . 0,00\%

CAPS $3,23 \%$

Ambulatório psiquiátrico no hospital geral - 3,23\%

Ambulatório c/ equipe espec. em S. M. 3,23\%

Leito psiquiátrico em hospital geral a 9,67\%

Oficina terapêutica

Atendimento c/ ajuda profissional referência

PACS c/ atendimento em Saúde Mental

PSF $\mathrm{c}$ / atendimento em Saúde M ental

UBS c/ atendimento em Saúde Mental

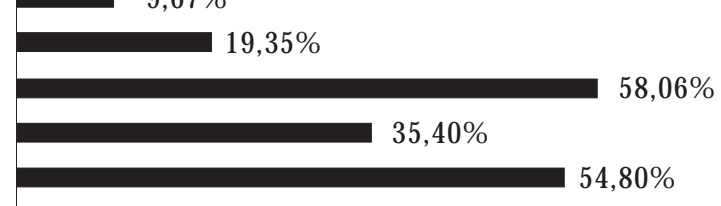

$58,06 \%$

Figura 1. Rede de serviços na área da saúde mental.

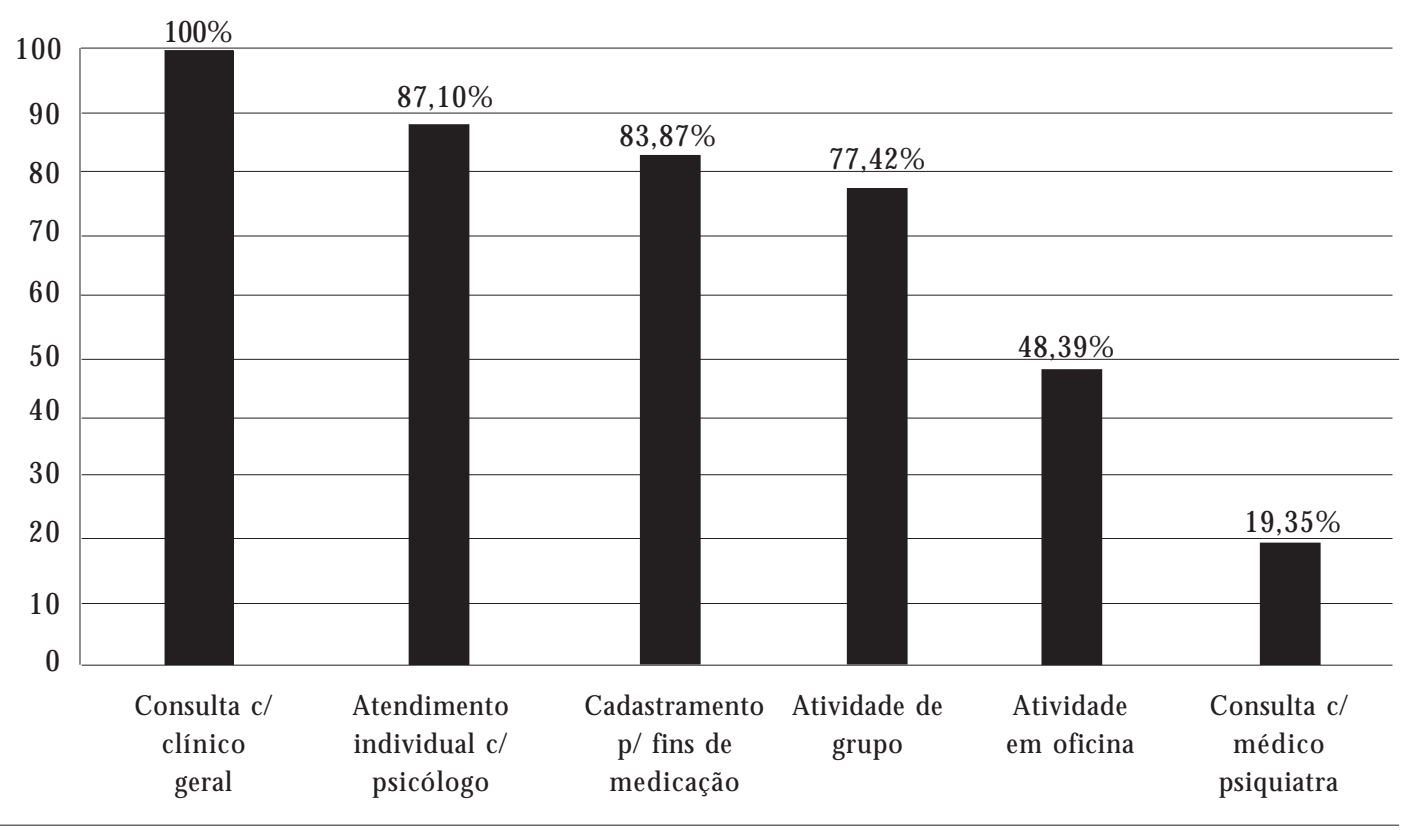

Figura 2. Cuidados/atividades desenvolvidos pelos municípios. 
Processo de referência e contra-referência

0 encaminhamento dos pacientes a hospitais psiquiátricos para, no retorno, receberem cuidados em suas próprias residências, sob a responsabilidade dos familiares (Figura 4), ocorre em $93,55 \%$ dos municípios pesquisados. A internação em hospitais gerais, para após o tratamento ficarem os pacientes, igualmente, aos cuidados dos familiares, ocorre em $41,94 \%$ dos municípios; $32,26 \%$ dos municípios, após os primeiros cuidados e medicação adequada, ainda na Unidade de Saúde, liberam os pacientes para continuarem o tratamento junto à família. Constata-se que apenas $6,45 \%$ dos municípios utilizam a prática de encaminhar seus pacientes aos hospitais psiquiátricos, para, quando do retorno, receberem cuidados em CAPS/família. Um deles é mantenedor de uma dessas instituições, enquanto o outro, pela proximidade e eventual acerto administrativo, beneficia-se do CAPS dePasso Fundo. 0 mesmo percentual $(6,45 \%)$ aparece no fluxo CAPS/domicílio, pelas razões expostas.

\section{Participação da área da Saúde M ental no Conselho Municipal da Saúde}

Em relação à participação deentidades e funcionários ligados à área da Saúde M ental nos Conselhos Municipais de Saúde, contatou-se que apenas $25,80 \%$ dos municípios concedem representação aos profissionais ou entidades que lidam com a Saúde M ental, especificamente. Os Conselhos Municipais deSaúde contam com a Associação dos Alcoólicos Anônimos, a Associação dos Psicólogos, um hospital geral como referência regional no tratamento de drogas e também com psicólogos. A pouca representação de entidades ligadas à Saú-

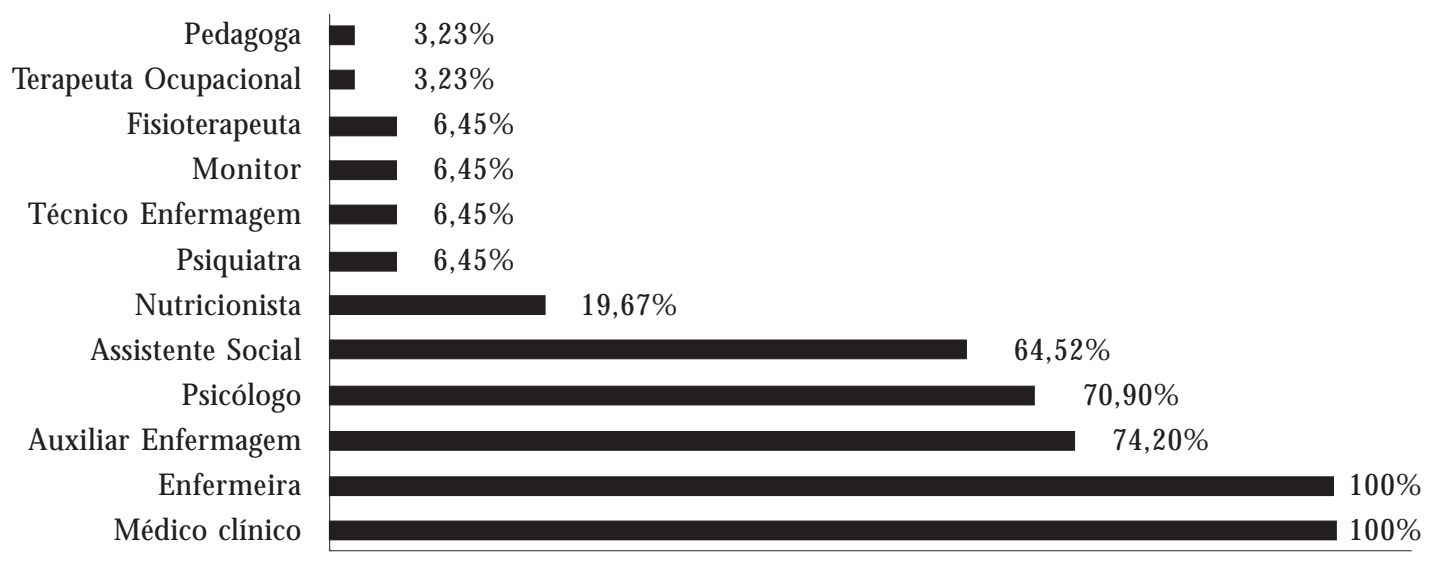

Figura 3. Profissionais a serviço da saúde mental.

Encam. p; CAPS/domicílio

Encami. p/ intern. em HP/CAPS

Encam. $\mathrm{p} /$ acompanh. domiciliar

Encam. p/ intern. em HP/domicílio

Encam. p/ intern. em HP/domicílio
$6,45 \%$

$6,45 \%$

$32,26 \%$

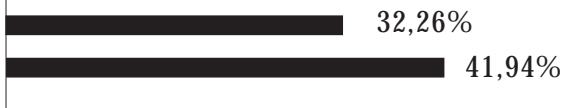

$93,55 \%$ 
deM ental dá-semais em razão da inexistência destas em municípios de pequeno porte do que, propriamente, pela não-deliberação da escolha.

Investimentos na Saúde Pública e na Saúde M ental

Sobre os investimentosfeitos pelos municípios no ano de $2002,81,69 \%$ deles responderam estarem os recursos para a Saúde M ental englobados no orçamento de Saúde Pública, que não há dotação própria para essa área, enquanto os demais, $18,31 \%$, abstiveram-se de fornecer essa informação. Quanto à aplicação de recursos municipais efetivamente ocorrida em 2002 , os percentuais foram muito variáveis, ficando numa faixa queaponta o menor com $11,15 \%$ e o maior com $23,41 \%$. $\mathrm{Na}$ verdade, este item não foi respondido por todos os municípios, pois nove (9) se abstiveram de fazê-lo, alegando falta de condições técnicas ou outras. Todavia, todos os informantes, em número de vinte e dois, atingiram, no ano em questão, 0 índiceestabelecido pela EmendaConstitucional $n$ 29. A média percentual aplicada na área da Saúde Pública desses municípios foi de $14,29 \%$.

\section{Internações em hospitais psiquiátricos}

Questionados sobre os critérios adotados nas internações de pessoas com transtorno mental, $54,80 \%$ dos municípios informaram que utilizam as internações em hospitais psiquiátricos somente nos casos considerados graves pelo médico ou pelo profissional de referência; $35,40 \%$ dizem usar a prática em algumas condições psicopatológicas, como psicose, al coolismo, dependência de drogas, transtornos psiquiátricos, esquizofrenia, transtorno bipolar, surtos psicóticos agudos, quadros demenciais graves, dentreoutras; $6,45 \%$ informaram providenciar internação em todos os casos, por não disporem de equipe preparada para lidar com pessoas que apresentam transtornos mentais, e $3,23 \%$ valem-se da internação independente das condições psicopatológicas do paciente, ou seja, transferem para hospitais psiquiátricos em todas as situações, quer sejam quadros psicóticos agudos ou crônicos.

Os dados contidos na Figura 5 permitem um cruzamento com as variáveis apresentadas na $\mathrm{Fi}$ gura 4 , na qual se constata que em $93,55 \%$ dos casos o portador de transtorno mental é encaminhado ao hospital psiquiátrico para, no retorno, receber cuidadosjunto aosfamiliares. Ou seja, os números apresentados na Figura 5, que aborda os crité rios de internações em hospitais psiquiátricos, evidenciam que as internações hospitalares nos casos graves correspondem a 54,80\%; em algumas condições psicopatológicas específicas, atingem 35,40\% e, nos demais casos, perfazem 9,68\%. O resultado da soma destes percentuais, comparado aos encaminhamentos para hospitais psiquiátricos, demonstra que os valores encontrados são coincidentes, isto é, retratam a realidade das transferências para hospitais psiquiátricos fora do município.

Registro de encaminhamentos para internações

A respeito dos procedimentos de registro de prontuários, prática considerada habitual e neces-

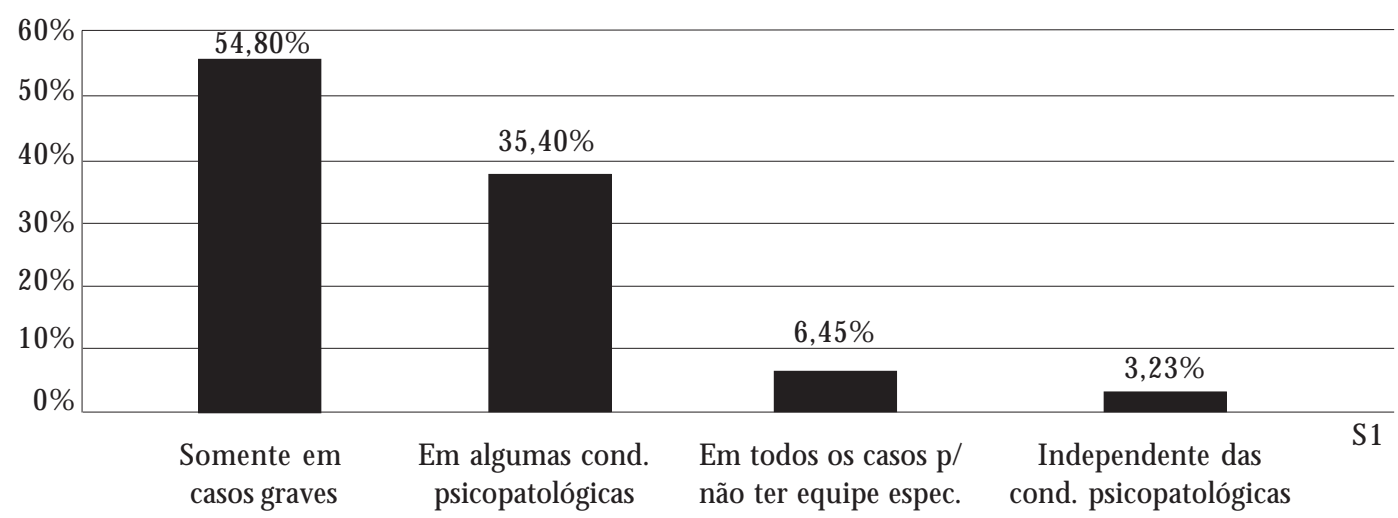

Figura 5. Critérios de internações de doentes mentais em hospitais psiquiátricos. 
sária quando do atendimento de pacientesnas UBS, $74,20 \%$ dos municípios informaram que, ao efetuarem o encaminhamento para internação em outros hospitais, registram devidamente a ocorrência, enquanto os demais $25,80 \%$ informaram nada registrar ou se omitiram de responder.

As informações colhidas a respeito dos registros deencaminhamentos de doentes mentais, cruzadas com os números apresentados na Figura 5 , retratam uma realidade que vai além do entendimento dos próprios percentuais. Enquanto se verifica que $25,80 \%$ dos municípios não realizam qualquer registro de encaminhamento dos pacientes, $32,26 \%$, percentual aproximado, após tratar os pacientes em suas UBS ou no PSF, encaminhamnos para acompanhamento domiciliar, o que leva a crer que esse universo de pessoas passa a não ter mais qualquer acompanhamento pelos profissionais da saúde, a não ser quando voluntariamente ou por necessidade imperiosa retornar às U BS, provocando, assim, o processo da "porta giratória".

\section{Discussão}

Investigando a inserção da assistência em Saúde M ental nos Planos M unicipais de Saúde, foi constatado que um número reduzido de gestores municipais incluiu nos projetos programas e ações que vieram a minimizar o sofrimento daquelas pessoas acometidas de transtornos mentais. N este aspecto, partindo do princípio de que os Planos M unicipais de Saúde devem merecer a aprovação do respectivo Conselho Municipal deSaúde, a quem cabe também fiscalizar as ações, conclui-se que a Saúde M ental, por não estar contemplada nem mencionada nos Planos M unicipais de Saúde, não éprioridade, nem meta paracumprimento em curto prazo, para os municípios da região do Alto U ruguai. Várias leituras podem derivar destes dados: a quase totalidade são municípios de peque no porte, predominantemente rurais, a não existência de vontade política para a implantação de serviços de Saúde M ental; o reduzido número de especialistas. Percebe-se que, apesar da totalidade dos municípios dispor de equipes do PSF, na prática ocorre uma dissociação mente/corpo: os casos de sofrimento psíquico são subvalorizados e encaminhados para outras instâncias, via de regra, 0 hospital psiquiátrico. Esta solução encontrada nos municípios pesquisados caminha na contramão da Reforma Psiquiátrica.

Ao identificar o tipo de assistência prestada nos diferentes níveis de aten ção, considerando os serviços na área da Saúde M ental e os cuidados/ativida- des desenvolvidos, a conclusão a que se chega, avaliando a realidade estampada nos números das $\mathrm{Fi}$ guras 1 e2, éque, nos municípios da região, prevalecem as consultas clínicas, como base da intervenção em Saúde M ental: ou os pacientes com transtornos mentais são atendidos nas Unidades Básicas ou nos Programas da Saúde da Família, em nível de atenção básica, por médicos generalistas, enfermeiras ou agentes de saúde, fato este preconizado como correto, se transcendesse 0 atendimento no modelo de consultas clínico-ambulatoriais, ou então são encaminhados a hospitais psiquiátricos. Consideramos desejável a adoção pelos profissionais que atuam na atenção básica do conceito de clínica ampliada, ou seja, a noção de contextualizar o indivíduo em sofrimento no seu entorno social. I sto implica uma mudança de perspectiva, na qual deverão prevalecer a responsabilização pela pessoa em sofrimento, a interdisciplinaridade, a horizontalidade, a adoção de um projeto terapêutico comum à equipee a inserção da família no tratamento. Também há que se considerar o respeito aos aspectos culturais de cada etnia, determinantes para a compreensão do processo saúde-doença.

Koga ${ }^{19}$, investigando o tipo de atuação em saúde mental no Programa Saúde da Família (PSF) do município de Maringá, entrevistou profissionais das equipes do PSF e famílias usuárias desse programa. Percebeu que os membros das equipes têm dificuldade para trabalhar no domicílio questões relativas à Saúde M ental, por não se sentirem preparados. As famílias avaliaram a atuação da equipe como boa; por outro lado, demonstraram insati sfação pela ausência de suporte, como número insuficiente deatendimentos, que prejudica a continuidade de tratamentos iniciados. A pesquisadora conclui que existe necessidade de preparo dos profissionais das equipes do PSF para realizar a assistência em Saúde M ental.

A parceria PSF e Saúde M ental não quer dizer treinamento das equipes de saúde da família em procedimentos simplificados da psiquiatria, mas uma construção recíproca e responsável de uma teoria, de uma prática e de uma ética, mediante o estabelecimento de um acordo político. Saúde $M$ ental ePSF interdeterminam-se, interpotenciamsee interdependem-se e implicam transformações profundas nas práticas do Estado, em todos os seus níveis ${ }^{15}$.

De acordo com os dados expressos no documento da Organização Mundial de Saúde/Organização Pan Americana de Saúde - OM S/OPAS ${ }^{20}$, a obtenção de soluções efetivas perpassa a concepção da abordagem da Saúde M ental pelo prisma da Saúde Pública. 0 relatório aponta as desigual- 
dades entre países e dentro do mesmo país em termos de recursos e formação de profissionais. Afirma que uma prestação apropriada de serviços em todos os níveis de aten ção perpassa estas questões. 0 documento traz recomendações de caráter geral para o desenvolvimento da atenção em SaúdeM ental, resultado de experiências cumulativas em muitos países com níveis de recursos diversos e evidenciados pelas pesquisas científicas. Dentreosdez itens, cinco remetem à comunidade: proporcionar tratamento na atenção primária; garantir atenção na comunidade; envolver as comunidades, famílias e os usuários; criar vínculos com outros setores e monitorizar a Saúde M ental na comunidade.

Sobre a participação dos profissionais e entidades que lidam com a Saúde M ental, nos ConseIhos Municipais de Saúde, o estudo apontou que em apenas um quarto dos municípios existe essa representação; a realidade permite a conclusão de que, se não há uma política em Saúde M ental nos municípios, é porque, igualmente, inexiste quem defenda, no colegiado, uma política própria para a área da Saúde M ental, pois é nessa instância que nascem as políticas públicas voltadas à saúde. É imprescindível que os profissionais assumam a condição de formadores de opinião, exercendo 0 poder de influenciar, quer os gestores municipais, quer os demais segmentos da sociedade, através da representação neste colegiado.

O cotidiano das instituições de saúde é o lugar comum onde, por um lado, se vivenciam conflitos e constatam limites e dificuldades, e que, de outro, pode transformar os atores em autores de projetos inovadores de construção de novas realidades em saúde. Dessemodo, parte-se do pressuposto de que a estruturação, o funcionamento organizacional e a ordenação específica dos processos de trabalho no interior das instituições de saúde podem ser desconstruídos e recriados cada vez e de novo, todos os dias, pois são socialmente produzidos ${ }^{21}$.

Os serviços de saúde destes municípios operam basicamente com profissionais generalistas, com pouco ou nenhum vínculo com a SaúdeM ental. Todos os municípios possuem em seus quadros ou então utilizam contratações autorizadas de médicos generalistas, ou, em al guns poucos casos, de profissional com alguma especialidade. Referindo estes dados, a priori não se constata falta de profissionais no atendimento da atenção básica nosmunicípios. 0 quese verifica éque osatendimentos são centrados no modelo do dano, da doença, ou seja, independentemente de a totalidade dos municípios deterem em seus quadros mé dicos generalistas e enfermeiras, 0 atendimento é eminentementemedicamentoso-ambulatorial.
Tanto a Saúde M ental como a Estratégia de Saúde da Família têm apresentado novas modalidades de cuidado do processo de adoecimento, produzindo tecnologias diversas que propiciam um melhor cuidado. Essa é uma preocupação que envolve as pessoas e as relações. 0 cuidado requer envolvimento com o outro, está ligado à idéia de coresponsabilizar-se pelo outro, de envolver-se com 0 sofrimento do outro, de solidarizar-se com o outro. Então, pressupõe vincular-se a alguém e isso requer disponibilidade para o outro, para o inusitado, para a relação 22 .

0 relatório da Organização M undial de Saúde ${ }^{20}$ prevê que, com a integração da atenção em Saúde M ental ao sistema de saúde geral, aumentará a de manda de generalistas e diminuirá a de especialistas em Saúde M ental. 0 documento sugere, entretanto, quedevepermanecer uma massa crítica deespecialistas para ministrar tratamento efetivo. No caso do PSF, deve-se apontar que a integralidade das ações é uma das filosofias do programa, havendo, desta forma, dissonância entreo preconizado eo executado.

Nos casos de encaminhamentos de pacientes para atendimento em níveis secundário e terciário, ficam expostas, de forma clara, as deficiências dos municípios. Ao estabelecerem o fluxo referência/ contra-referência, intra e intermunicípios, no re torno, os pacientes são deixados sob responsabilidade das famílias, sem um acompanhamento dos profissionais que os atenderam na aten ção básica. É fundamental que o paciente seja contra-referenciado à Unidade Básica de Saúde para continuidade do tratamento, não perdendo o vínculo com os profissionais que iniciaram o processo. Cabe ressaltar que esse procedimento - encaminhar o paciente ao hospital psiquiátrico para, no retorno, ser atendido pela família - ocorreem $93,55 \%$ dos municípios. Os números revelam que prevalece alógica da "ambulancioterapia", ocorrendo sistematicamente o círculo internação-alta-reinternação.

A persistência de antigos problemas e limites, arraigados no cotidiano das instituições de saúde, tem dificultado em grande parte as transformações das práticas sanitárias e da medicina, numa perspectiva de mudança efetiva do modelo assistencial desaúde. Evidenteestá que, tais problemas elimites se relacionam com contextos desiguais, nos quais habitam distintas percepções e concepções sobre 0 processo saúde e doença, o que tem gerado descompasso ou mesmo desencontro entre os objetivos e aspirações dos atores envolvidos. Esses contextos referem-se às dimensões econômica, cultural, social e política, nos quais a ação em saúde se apresenta como um espaço de representação de interesses, desejos e sentidos ${ }^{21}$. 
Relativamente à alocação de recursos financeiros para a área da Saúde Pública, constatou-se, sem nenhuma exceção, que os municípios disponibilizam percentuais acima daqueles estabelecidos

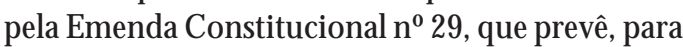
0 ano de 2002, 10,2\% deum elenco de receitas próprias, definidas no próprio diploma ${ }^{23}$. Todavia, em se tratando de alocação de recursos para a área da Saúde M ental, constatou-se que somente um município informou ter verba própria para a Saúde M ental, englobada na Saúde Pública.

Deacordo com Alves ${ }^{24}$, a contabilização degastos na assistência psiquiátrica, historicamente, sempre se referiu às despesas com internações em hospitais psiquiátricos, por ainda se constituírem na principal modalidade de tratamento para pessoas com transtornos mentais. Desta forma, as séries históricas de gastos sempre se reportavam ao regime de internação. $\mathrm{Na}$ avaliação do autor, decorridos dez anos da Portaria no 189, que alterou o financiamento das ações e serviços de Saúde M ental, há ainda um descompasso entre 0 acumulado político e os gastos com internação em hospitais psiquiátricos e em serviços comunitários. Entretanto, o autor visualiza que a tendência é de superação do modelo manicomial.

Em consonância com os dados expressos no

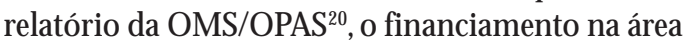
da Saúde M ental deverá ser efetivamente destinado aos serviços através de especificação técnica de critérios integrantes de um pacote geral de intervenções básicas ou essenciais, para que o setor público se comprometa efetivamente a financiar, estando ou não especificada no orçamento, a quantia a ser aplicada nestes serviços. 0 documento ressalta a necessidade de melhorar a alocação arbitrária ou simplesmente histórica de recursos. Salienta também que a aplicação de um volume substancialmente maior de recursos públicos na Saúde M ental não irá garantir a eficiência ou distribuição eqüitativa. A distribuiçã̃o de recursos com basenas necessidades seria um modo mais eqüitativo; entretanto, o relatório aponta para a premência de uma concordância entre "necessidade" eprioridade. Ressalta que isto já se constitui em um problema no caso de doenças físicas, tornando-se mais complicado na área da Saúde M ental. 0 relatório destaca a importância do setor público na gestão dos re cursos, para que a Reforma Psiquiátrica possa efetivamente se consolidar. Isto é verdadeiro na medida em que a Reforma Psiquiátrica tem como palco o município; quando esteconsegue absorver eatender a demanda nos três níveis de atenção, os encaminhamentos para hospitais psiquiátricos diminuem ou são desnecessários.
Pertinenteàintenção deseidentificar seainternação psiquiátrica é de fato concebida como última alternativa a ser adotada - fato de suma importância no estudo - conclui-se que, amparados em crité rios diversos, osmunicípiosutilizam, invariavelmente, a prática de encaminhar seus pacientes para serem atendidos em outros níveis. Os dados apontam que um quarto dos municípios não registra quando o paciente é encaminhado para hospitais psiquiátricos, deduzindo-se daí quenão haverá posterior acompanhamento por parte da Secretaria Municipal de Saúde. Não se consubstancia, desta forma, o processo de referência/contra-referência.

Convém ressaltar que a cidade pólo regional é a cidade que abriga um hospital geral tido como referência regional no atendimento ao portador detranstorno mental, por dispor demelhores condições de recursos humanos, instalações e equipamentos, inexistentes nos demais municípios. Entretanto, face à excessi va demanda, faz-se necessário estruturar melhor as UBS, PSF ePACS, qualificando os recursos humanos na abordagem à saúde/doença mental. Esses procedimentos modificariam o organograma de atendimento ao sofrimento mental, transformando essas instituições e programas efetivamente em portas de entrada do sistema de atendimento na área mental.

Trazemos alguns conceitos denominados de síntese metodológica25: o paciente, antes de uma formação psicopatológica, é um cidadão; a não dissociação entre sofrimento físico e mental. As condições ambientas, sociais e mentais formam partes de ecologias inter-relacionadas; a psicose, as experiências de sofrimento, de violência, acontecem em territórios determinados: na família, na comunidade, nos universos existenciais das pessoas. 0 paciente é o grupo familiar todo, a observação, a escuta e a pesquisa devem ser orientadas para a família; 0 atendimento primordial, às famílias com maior dificuldade e vulnerabilidade. Os profissionais deverão abandonar o ideologema família desestruturada. Procurarão entender os modos que cada cultura possui para compreender o sofrimento e superá-lo. A real ização de parcerias será fundamental para operar os processos de reabilitação psicossocial. Para isso, deverá ser comprometida toda a organização sanitária e serão priorizadas as conexões com políticas públicas e com os recursos existentes nas comunidades.

Os pressu postos citados servem de guia balizador para as ações desenvolvidas em Saúde M ental comunitária. Poderão ser aplicados não somente no contexto comunitário, mas também na atenção terciária. Dos pressupostos acima, pode-se fazer as seguintes leituras: a necessidade de capacitação de 
profissionais para que visualizem o ser humano em sofrimento psíquico no seu todo: físico, mental, meio ambiente e cultura; o domínio de intervenções nos diversos campos/áreas geográficas; a não estigmatização das famílias através de rótulos, mas sim o estabelecimento de parcerias com as mesmas; 0 atendimento prioritário aos mais necessitados e grupos vulneráveis.

As ações precisam estar onde às pessoas estão; inverte-se o paradigma asilar é proibido isolar para tratar, o sujeito não é a especificidade individual, mas o conjunto de vínculos, de relações compartiIhadas. A acessibilidadegeográfica traduz-sepela facilidadedeser atendido, a acessibilidade política traduz-sepela capacidadedeplanejar edecidir demodo participativo ${ }^{15}$.

0 território não é composto apenas pelo seu bairro, mas pelo conjunto de referências socioculturais e econômicas que fazem parte de seu cotidiano, de seu projeto de vida, de sua inserção no mundo. Um serviço só poderá dar um uso prático ao conceito de território se estiver localizado em um bairro, emoldurado pelas referências sociais e culturais daquela comunidade ${ }^{26}$.

O Programa Saúde da Família se coloca como principal dispositivo para o exercício de uma nova forma de assistência em Saúde M ental. Serviços como osCAPS são osorganizadores da redee como tal deveriam buscar o estreitamento de laços entre o campo da Saúde M ental e do PSF. Para tanto, seránecessário solidificar seus princípiosfundamentais para agenciar o processo de reconstrução das práticas, sem incorrer no erro de reproduzir as técnicas tão questionadas do modelo hospitalocêntrico ao se aproximar das comunidades ${ }^{22}$.

Desta forma, entendemos que os municípios de pequeno porte deverão investir na capacitação dos profissionais da atenção básica para que estes possam operar tendo como pressupostos norteadores de sua prática os princípios da Reforma Psiquiátrica. Para que isto efetivamente possa se concretizar, há a necessidade de estabel ecer uma rede dentro de cada município, a identificação de leitos psiquiátricos em unidades de hospitais gerais, além de campanhas para desmitificar a doença mental na comunidade. Faz-se também premente a sensibilização do poder público, através dos gestores municipais para esta questão. Sobretudo, há que se considerar que há um retorno político decorrente das transferências para hospitais psiquiátricos.

Os resultados da pesquisa foram devolvidos aos municípios pesquisados através de reuniões com os gestores ecom os profissionais. I gualmen- te, os dados obtidos foram encaminhados à $11^{\text {a }}$ Coordenadoria Regional de Saúde e à Coordenação Estadual deSaúde M ental etransmitidos à academia nos cursos de graduação afins, objetivando um olhar crítico dos futuros profissionais para a realidade encontrada. Entendemos que as ações futuras dos profissionais em campo dependem do tipo de experiência durantea vida acadêmica.

\section{Consideraçõesfinais}

A Lei n ${ }^{\circ} 10.216 / 01$, quetrata da Reforma Psiquiátrica em nosso país, foi sancionada no dia 6 de abril de2001, tendo, portanto, quasequatro anos deexistência. Todavia, há que se mencionar que, já em 1992, o Rio Grande do Sul possuía uma legislação específica sobre o assunto. A par disso, o M inisté rio da Saúdeiniciava nessa época a emissão de uma vasta legislação que viria a nortear todas as ações no sentido detratar adequadamenteas pessoas acometidas de transtornos mentais. Deste modo, passados quase quinze anos, o processo de implantação da Reforma Psiquiátrica deveria encontrar-se em plena consolidação, em todo o país, e em especial no Rio Grande do Sul, o que, definitivamente, não foi o que se verificou com o presente estudo.

Os dados aqui apresentados permitem afirmar que a questão da municipalização da saúde mental na região do Alto Uruguai é ainda incipiente e sua concretização depende fundamentalmenteda vontade política dos gestores, da capacitação técnica dos profissionais, da real inserção das ações de Saúde M ental na atenção básica, particularmente nos Programas de Saúde da Família, do envolvimento crescente dos familiares, da conscientização e do reconhecimento da sociedade para a questão da cidadania das pessoas portadoras de transtornos mentais, cujos direitos estão consubstanciados na Constituição do país.

O mapeamento das ações em Saúde M ental no Sistema Ú nico de Saúde poderá, a partir do processo deatenção, fornecer indicadores das práticas dos serviços do ponto de vista dos atores sociais, para a construção de parâmetros que possam ser universalizados e instrumentalizar os operadores. Espera-se, através desta avaliação, alavancar a inclusão do cuidado à Saúde Mental no Sistema Ú nico de Saúde, com vistas à sensibilização do poder público e construção de práticas queincorporem o cuidado à saúde mental na aten ção básica, para que efetivamente a Reforma Psiquiátrica possa se consolidar em nosso país, para a superação do modelo manicomial obsoleto ainda vigente. 


\section{Colaboradores}

G Consoli elaborou o projeto, realizou a pesquisa bibliográfica, participou da elaboração do instrumento, coordenou a coleta, a organização ea análise de dados. A Hirdes orientou a construção do desenho da pesquisa, participou da elaboração do instrumento, da análise dos dados e da redação do artigo. J Costa fez a revisão do método.

\section{Referências}

1. Organização Mundial da Saúde. Organização Panamericana de Saúde. Declaração de Caracas. Conferência Regional para a Reestruturação da Atenção Psiquiátrica na América Latina no Contexto dos Sistemas locais de Saúde (SILOS). 14 de novembro de 1990. Genebra: Organização M undial da Saúde; 1990.

2. Barros DD. Cidadania versus periculosidade social: a desinstitucionalização como desconstrução de um saber. In: Amarante P, organizador. Psiquiatria social e reforma psiquiátrica. $2^{2}$ ed. Rio de Janeiro: Fiocruz; 2002. p. 171-195.

3. Amarante P. O Homem e a serpente: outras histórias para a loucura e a psiquiatria. Rio de Janeiro: Fiocruz; 2000.

4. Amarante P. Loucos pela vida: a trajetória da reforma psiquiátrica no Brasil. 2a ed. Rio de Janeiro: Fiocruz; 1998.

5. Amarante $P$, organizador. Psiquiatria social e reforma psiquiátrica. 2a ed. Rio de Janeiro: Fiocruz; 2002.

6. Saraceno B. Libertando identidades: da reabilitação psicossocial à cidadania possível. Rio de Janeiro: Instituto Franco Basaglia/Te Corá; 1999.

7. Brasil. M inistério da Saúde. Legislação em saúde mental. 2a ed. Brasília: Ministério da Saúde; 2001.

8. Brasil. Constituição da República Federativa do Brasil. São Paulo: Saraiva; 2002.

9. Brasil. Lei $n^{\circ} 8.080$. Dispõe sobre as condições para a promoção, proteção e recuperação da saúde, a organização e o funcionamento dos serviços correspondentes e dá outras providências. Diário Oficial da União 1990; 19 set.

10. Brasil. M inistério da Saúde. Relatório Final da $2^{\mathrm{a}}$ Conferência Nacional de Saúde M ental. Brasília: M inistério da Saúde; 1994.

11. Brasil. M inistério da Saúde. Normas O peracionais Básicas do Sistema Ú nico de Saúde - SUS. 0 que você precisa saber sobre o Sistema Ú nico de Saúde. [acessado 2002 jul 28]. Disponível em: http://www.apm.org.br

12. Brasil. M inistério da Saúde. Relatório Final da $3^{a}$ Conferência Nacional de Saúde M ental. Brasília: M inistério da Saúde; 1994.

13. Brasil. Ministério da Saúde. Base de dados do DATASUS. [acessado 2002 fev 26]. Disponível em: http:// www.datasus.gov.br

14. Secretaria de Estado da Saúde e M eio Ambiente do Rio Grande do Sul. Guia de serviços de saúde mental Rio Grande do Sul. Porto Alegre: Secretaria de Saúde e M eio Ambiente; 2002.

\section{Agradecimentos}

Aos profissionais da $11^{\text {a }}$ Coordenadoria Regional de Saúde e aos profissionais de saúde dos municípios investigados. À professora Laura Chiamenti pela revisão do texto.
15. Sampaio JJC, Barroso CMC. Centros de Atenção Psicossocial e Equipes de Saúde da Família: diretrizes e experiências no Ceará. In: Jatene A, Lancetti $A$, organizadores. Saúde Loucura, 7. Saúde mental e saúde da família.2a ed. São Paulo: Hucitec; 2001.

16. Fundação Instituto Brasileiro de Geografia e Estatística. Pesquisa de informações básicas municipais. [acessado 2004 fev 28]. Disponível em: http://www. ibge.gov.br

17. Brasil. Conselho Nacional de Saúde. Resolução 196 de 10 de outubro de 1996. Dispõe sobre as diretrizes e normas regulamentadoras de pesquisa envolvendo seres humanos. Brasília: O Conselho;1996.

18. Declaração de Helsinque. Associação M édica M undial. Declaração para orientação de médicos quanto a pesquisa biomédica envolvendo seres humanos. [acessado 2006 ago 22]. Disponível em: http://www. ufmt.br/cep_hujm/textos_para_estudo/declaracao_ helsinque.htm

19. Koga M. Programa Saúde da Família de Maringá: a opinião sobre a atenção à saúde mental [tese]. Ribeirão Preto (SP): Escola de Enfermagem de Ribeirão Preto, Universidade de São Paulo; 2003.

20. Organização Mundial da Saúde. Organização Panamericana de Saúde. Relatório sobre a saúde no mundo 2001. Saúde mental: nova concepção, nova esperança. Genebra: Organização M undial da Saúde; 2001.

21. Campos GWS. Um método para análise e co-gestão de coletivos. São Paulo: Hucitec; 2000.

22. Souza AC. Em tempos de PSF... novos rumos para a saúde mental [dissertação]. Rio de Janeiro (RJ): Escola Nacional de Saúde Pública Sergio Arouca; 2004.

23. Brasil. Emenda 29 da Constituição da República Federativa do Brasil. Altera os arts. 34, 35, 156, 160, 167 e 198 da Constituição Federal e acrescenta artigo ao Ato das Disposições Constitucionais Transitórias, para assegurar os recursos mínimos para o financiamento das ações e serviços públicos de saúde. Diário Oficial da U nião 2000; 14 set.

24. Alves DSN . Financiamento na saúde mental. Rev Saúde 2001; 2:26-27.

25. Lancetti A, organizador. Saúde mental e saúde da família. São Paulo: Hucitec; 2000.

26. Carvalho JM. Cidadania no Brasil: o longo caminho. Rio de Janeiro: Civilização Brasileira; 2002.

Artigo apresentado em 26/03/2006

Aprovado em 04/07/2006

Versão final apresentada em 25/09/2006 